\title{
Evaluation of Food-Grade Dent Corn Hybrids for Severity of Fusarium Ear Rot and Fumonisin Accumulation in Grain
}

C. E. Kleinschmidt and M. J. Clements, Department of Crop Sciences, University of Illinois, Urbana 61801; C. M. Maragos, United States Department of Agriculture-Agricultural Research Service (USDA-ARS) Mycotoxin Research Unit, Peoria, IL 61604; and J. K. Pataky and D. G. White, Department of Crop Sciences, University of Illinois, Urbana

\begin{abstract}
Kleinschmidt, C. E., Clements, M. J., Maragos, C. M., Pataky, J. K., and White, D. G. 2005. Evaluation of food-grade dent corn hybrids for severity of Fusarium ear rot and fumonisin accumulation in grain. Plant Dis. 89:291-297.

Fumonisins produced by Fusarium verticillioides $($ syn $=F$. moniliforme) and $F$. proliferatum have been associated with potentially serious toxicoses of animals and humans. Thus, hybrids with low fumonisin accumulation in grain will be valuable for the production of corn-based human food products. We evaluated 68 food-grade dent corn hybrids for severity of Fusarium ear rot and fumonisin accumulation in grain in inoculated trials in Urbana, IL in 2000 and 2001. Our inoculation technique was successful in initiating fumonisin accumulation that allowed discrimination among hybrids. We identified several hybrids that could have acceptable levels $(<4 \mu \mathrm{g} / \mathrm{g})$ of fumonisin accumulation in Illinois in most years. Twenty-six hybrids with low or high fumonisin accumulation in 2000 were reevaluated in noninoculated trials at three locations in Illinois in 2001. Fumonisin concentration in grain at all three locations was relatively low; thus, separation of hybrids was poor. At two locations, those hybrids with the highest fumonisin concentration in grain also had high concentrations following inoculation. However, one hybrid that had relatively low fumonisin concentration following inoculation had unacceptable levels of fumonisin $(5 \mu \mathrm{g} / \mathrm{g})$ in natural conditions. Therefore, hybrids need to be evaluated by inoculation and further evaluated at locations where the environment favors fumonisin accumulation.
\end{abstract}

Additional keyword: maize

A group of mycotoxins known as the fumonisins has been associated with Fusarium ear rot of corn (Zea mays L.) since 1988 (13). Fumonisins are secondary metabolites of several Fusarium Link species, including Fusarium. verticillioides (Sacc.) Nirenberg (syn $=F$. moniliforme J. Sheld.) and $F$. proliferatum (T. Matsushima) Nirenberg, that are found worldwide in temperate regions where corn is produced (24). Generally, high fumonisin accumulation in grain has been associated with environmental conditions, such as drought and high relative humidity, that frequently

Corresponding author: D. G. White

E-mail: donwhite@uiuc.edu

Current address for M. J. Clements: USDA-ARS Corn Host Plant Resistance Research Unit, Mississippi State, MS 39762.

This article presents results of research only and is based upon work supported by CFAR project number 01E-003-4. Conclusions, opinions, and recommendations expressed in this publication are those of the authors and do not necessarily reflect the views of CFAR. Mention of trade names or proprietary products does not constitute endorsement by the University of Illinois.

Accepted for publication 22 October 2004.

DOI: 10.1094/PD-89-0291

(C) 2005 The American Phytopathological Society occur in the southeastern United States $(9,17,23,29,36)$.

Although a cause-and-effect relationship has not been demonstrated clearly, potentially serious human health disorders have been associated with consumption of corn products contaminated with fumonisin $(5,6,10,26,31,37,40,41)$. Fumonisin in corn-based human food is not common in the United States, although contamination has been reported in corn meal $(4,20,30,32,38,39)$, corn grits (39), muffin mix $(4,30)$, corn bread mix (4), tortilla chips (4,20), tortillas (37), and beer (19). The United States Food and Drug Administration (FDA) recommends various maximum levels for fumonisins $\left(\mathrm{FB}_{1}+\mathrm{FB}_{2}+\right.$ $\mathrm{FB}_{3}$ ) in corn and corn products intended for human consumption, including a concentration of total fumonisin at $2 \mu \mathrm{g} / \mathrm{g}$ or less in degermed dry milled corn products (e.g., flaking grits, corn grits, corn meal, corn flour with fat content of $<2.25 \%$, dry weight basis), $3 \mu \mathrm{g} / \mathrm{g}$ or less in cleaned corn intended for popcorn, and $4 \mu \mathrm{g} / \mathrm{g}$ or less in dry milled corn bran cleaned for masa production and whole or partially degermed dry milled corn products (e.g., flaking grits, corn grits, corn meal, corn flour with fat content of $\geq 2.25 \%$, dry weight basis) (42). Concentration of fumonisin in corn grain from much of the Midwest frequently is nondetectable to 5 $\mu \mathrm{g} / \mathrm{g}$, although concentrations can be greater than $5 \mu \mathrm{g} / \mathrm{g}$ in some years $(1,24,25,34,45)$. However, fumonisin concentration in corn grain can exceed guidelines established by the FDA ( 2 to $4 \mu \mathrm{g} / \mathrm{g}$ ). Grain elevators in central Illinois will not accept grain of food-grade corn with fumonisin concentration at $>4 \mu \mathrm{g} / \mathrm{g}$ and some grain elevators will reject grain at $>3 \mu \mathrm{g} / \mathrm{g}$. Thus, a substantial portion of the corn crop in the United States could be affected when environmental conditions favor fumonisin accumulation in grain.

Although several methods of reducing fumonisin concentration in unprocessed grain or processed corn-based food products have been reported $(2,18,21,22,27$, 35,43 ), evidence that these methods reduce toxicity of contaminated grain has not been clearly demonstrated. For example, fumonisin can be converted into hydrolyzed, biologically active forms that remain toxic $(3,12,18,43)$. A more efficient means of preventing fumonisin contamination in corn-based food products is planting hybrids that are highly resistant to Fusarium ear rot and fumonisin accumulation in grain. Relative susceptibility or resistance of food-grade dent corn hybrids to fumonisin accumulation in grain has not been reported; therefore, it is unknown if highly resistant (fumonisin at $<2 \mu \mathrm{g} / \mathrm{g}$ in all environments) food-grade hybrids are commercially available.

The primary objective of this study was to determine the relative range of susceptibility or resistance of commercial foodgrade corn hybrids to Fusarium ear rot and fumonisin accumulation in grain. A secondary objective was to compare fumonisin concentrations in grain resulting from an injection inoculation technique we developed and fumonisin concentrations resulting from natural infection.

\section{MATERIALS AND METHODS}

Inoculated trials. Seed of 68 foodgrade dent corn hybrids were planted at the University of Illinois Crop Sciences Research and Education Center, Urbana on 28 April 2000 and 2 May 2001. The 68 food-grade dent corn hybrids consisted of 33 white-kernel hybrids, seven blue-kernel hybrids and 28 yellow-kernel hybrids. Hybrids were selected based on diversity among commercial corn companies and commercial use in the Midwestern United 
States. The experimental design was a randomized complete block with two replicates. Experimental units were single rows consisting of 24 plants. Rows were $5.3 \mathrm{~m}$ long (plus a fallow alley of $\pm 0.5 \mathrm{~m}$ ) and spaced $0.8 \mathrm{~m}$ apart.

Cultural practices were similar between the experiments in 2000 and 2001. The only difference was that the experiment in 2000 was grown in a field that was planted with corn the previous year and the experiment in 2001 was grown in a field that was planted with soybean the previous year. The soil type of both fields is a Drummer silty clay loam (fine-silty, mixed, superactive, mesic Typic Endoaquolls) with a $\mathrm{pH}$ of approximately 6.7. The fields were fall chisel plowed and then worked with a Sunflower land finisher in the spring. Nitrogen was spring applied at the rate of 200 $\mathrm{kg} \mathrm{ha}^{-1}$. The insecticide tefluthrin (Force 3G; Syngenta Crop Protection, Inc., Greensboro, NC) was applied in-furrow at planting. Metolachlor (Dual II Magnum; Syngenta Crop Protection, Inc.) and atrazine (AAtrex Nine-O; Syngenta Crop Protection, Inc.) were applied preplant to control weeds.

Inoculum was prepared from three isolates of $F$. verticillioides (numbers 42, 150, and 152) and three isolates of $F$. proliferatum (numbers 19, 37-2, and 310) that produced severe Fusarium ear rot when a blend of isolates is injected into corn ears (7). One isolate of $F$. verticillioides (number 152) later was found not to produce fumonisin in grain (7). All six isolates are maintained at the University of Illinois and were isolated from corn grain in the Midwestern United States. Isolates were grown on potato dextrose agar (Becton Dickinson and Company, Sparks, MD) at approximately $25^{\circ} \mathrm{C}$ under $12 \mathrm{~h}$ of diurnal fluorescent light for 7 to 14 days.

Inoculum was prepared from an equal number of cultures of the six isolates. Deionized water was added to the cultures and mixed using a blender (model 700; Waring Commercial, Torrington, CT). The resulting propagule suspension was strained through two layers of cheesecloth, diluted with tap water to a concentration of $10^{6}$ conidia $/ \mathrm{ml}$ as determined with a hemacytometer, and amended with Tween 20 surfactant (polyoxyethylene 20-sorbitan monolaurate; Fisher Biotech, Fairlawn, $\mathrm{NJ}$ ) at $0.2 \mathrm{ml} / \mathrm{liter}$. Inoculum was used within $2 \mathrm{~h}$ of preparation.

Inoculations were accomplished with backpack sprayers (model 425; Solo Inc., Newport News, VA) equipped with an injection device that has been described (8). Spore suspension $(10 \mathrm{ml})$ was injected through the husk leaves into the side of the primary ear of all plants at the R2 (blister) growth stage (33). The $2.5-\mathrm{cm}$ needle allowed for placement of the inoculum between the kernels and husk. Injections destroyed one to three kernels. All primary ears in an experimental unit were har- vested at approximately $18 \%$ grain moisture, rated visually for severity of Fusarium ear rot by estimating percentage of the ear with symptoms, and dried with forced air at $32^{\circ} \mathrm{C}$ to approximately $14 \%$ grain moisture. Grain was shelled from primary ears and bulked by experimental unit. Bulked grain was ground with a Romer grinding/subsampling mill (Romer Labs, Inc., Union, MO) to pass through a $1-\mathrm{mm}$ mesh. Ground grain was analyzed for fumonisin concentration with a competitive-direct enzyme-linked immunosorbent assay (ELISA) that has been described (8).

Effects of years, replicates, and hybrids on fumonisin concentration in grain and severity of Fusarium ear rot were analyzed with the general linear model (GLM) procedure of Statistical Analysis System (SAS) software (SAS Institute, Cary, NC). Years and replicates were considered random terms in models, and hybrids were considered fixed. Data from individual years were analyzed and presented separately if a significant year-hybrid interaction was detected for either fumonisin concentration in grain or ear rot severity. Differences between hybrids within years were determined with Fisher's protected least significant difference (LSD) test (28). Concentration of fumonisin was transformed by the equation $y=\ln$ (fumonisin concentration +1 ) to normalize residuals. Fusarium ear rot ratings were transformed by the equation $y=\log _{10}$ (percent ear rot severity +1$)$ to normalize residuals. Pearson's correlation coefficients for fumonisin concentration and ear rot severity were calculated with untransformed treatment means within years. Weather information was obtained from the Midwest Regional Climate Center, Champaign, IL.

Noninoculated trials. Twenty-six hybrids, selected on the basis of low or high fumonisin concentration in grain in 2000 , were evaluated in noninoculated trials at three locations in 2001. Noninoculated trails could not be repeated an additional year due to a lack of availability of seed for many of the commercial hybrids. Seed of the selected hybrids was planted on 19, 24, and 26 April in Brownstown (southcentral), Carbondale (southern), and Dwight (northern), IL, respectively. Cropping history was not available for these trials. The experimental design was a randomized complete block with three replicates. Experimental units were four row plots. Rows were $6.9 \mathrm{~m}$ long (plus a fallow alley of $\pm 0.5 \mathrm{~m}$ ) and spaced $0.8 \mathrm{~m}$ apart. Individual rows included 34 plants at Brownstown and Carbondale and 37 plants at Dwight.

Cultural practices at the three locations were similar. At Brownstown, the soil type is a Cisne silt loam (fine, smectitic, mesic Mollic Albaqualfs). A finishing tool was used in the spring. Nitrogen was spring applied at the rate of $143 \mathrm{~kg} \mathrm{ha}^{-1}$. Ace- tochlor (Degree; Monsanto Company, St. Louis, MO) and atrazine (Aatrex; Syngenta Crop Protection, Inc.) were applied preplant and nicosulfuron (Accent; DuPont Crop Protection, Wilmington, DE) and atrazine (Aatrex; Syngenta Crop Protection, Inc.) were applied post planting to control weeds. At Carbondale, the soil type is a Stoy silt loam (fine-silty, mixed, superactive, mesic Fragiaquic Hapludalfs). The field was disked and field cultivated in the spring. Nitrogen was spring applied at the rate of $161 \mathrm{~kg} \mathrm{ha}^{-1}$. Atrazine and metolachlor (Bicep; Syngenta Crop Protection, Inc.) and atrazine (Aatrex; Syngenta Crop Protection, Inc.) were applied to control weeds. At Dwight, the soil type is a Elliot silt loam (fine, illitic, mesic Aquic Argiudolls). The field was disked in the fall and field cultivated in the spring. Nitrogen was fall applied at the rate of $193 \mathrm{~kg} \mathrm{ha}^{-1}$. Acetochlor (TopNotch; Dow AgroSciences, Indianapolis, IN) was applied preplant and atrazine and bentazon (Laddok; Micro Flo Company, Memphis, TN) were applied post planting to control weeds.

Grain from the two center rows of each plot was machine harvested and dried with forced air at $32^{\circ} \mathrm{C}$ to approximately $14 \%$ grain moisture. Severity of Fusarium ear rot was not evaluated due to machine harvesting. Grain was ground and analyzed for fumonisin concentration as described previously. Pearson's correlation coefficients for fumonisin concentration in grain were calculated with untransformed treatment means except for trials having little variation in fumonisin concentration among hybrids tested.

Effects of locations, replicates, and hybrids on fumonisin concentration in grain were analyzed with the GLM procedure of SAS. Locations and replicates were considered random terms in models and hybrids were considered fixed. Data from individual locations are presented separately because fumonisin concentration in grain was affected significantly by the location-hybrid interaction. Differences between hybrids within locations were determined with Fisher's protected LSD test. Fumonisin concentration was transformed with the equation $y=\ln$ (fumonisin concentration +1 ) to normalize residuals. Weather information was obtained from the Illinois Climate Network compiled by the Illinois State Water Survey, Champaign, IL.

\section{RESULTS}

Inoculated trials. Grand mean temperature for June, July, and August 2000 was $22.5^{\circ} \mathrm{C}\left(0.4^{\circ} \mathrm{C}\right.$ below average $)$. Rainfall and growing degree days $\left({ }^{\circ} \mathrm{D}\right.$; base 50$)$ during this same period totaled $26.8 \mathrm{~cm}$ $\left(5.1 \mathrm{~cm}\right.$ below average) and $2,052^{\circ} \mathrm{D}$, respectively. Precipitation was greatest after pollination. Ear rot severity ranged from 1 to $52 \%$. Fumonisin concentration in grain ranged from 4 to $255 \mu \mathrm{g} / \mathrm{g}$ (Table 1). 
Table 1. Transformed and nontransformed fumonisin concentration in grain and Fusarium ear rot severity for 68 food-grade dent corn hybrids evaluated at Urbana, IL in 2000 and $2001^{\text {a }}$

\begin{tabular}{|c|c|c|c|c|c|c|c|c|c|}
\hline \multirow[b]{3}{*}{ Hybrid } & \multirow[b]{3}{*}{ Kernel color } & \multicolumn{4}{|c|}{ Fumonisin concentration $(\mu \mathrm{g} / \mathrm{g})$} & \multicolumn{4}{|c|}{ Fusarium ear rot $(\%)$} \\
\hline & & \multicolumn{2}{|c|}{2000} & \multicolumn{2}{|c|}{2001} & \multicolumn{2}{|c|}{2000} & \multicolumn{2}{|c|}{2001} \\
\hline & & $\mathbf{T}$ & $\mathbf{N}$ & $\mathbf{T}$ & $\mathbf{N}$ & $\mathbf{T}$ & $\mathbf{N}$ & $\mathbf{T}$ & $\mathbf{N}$ \\
\hline Zimmerman Z64W & White & 5.5 & 255 & 2.9 & 20 & 1.4 & 28 & 0.9 & 7 \\
\hline Vinyard VX 4319W & White & 5.5 & 253 & 3.1 & 25 & 1.2 & 17 & 0.8 & 5 \\
\hline Pioneer $33 \mathrm{~T} 90$ & Yellow & 5.5 & 252 & 2.6 & 14 & 1.4 & 26 & 0.6 & 4 \\
\hline Asgrow RX951W & White & 5.3 & 203 & 2.1 & 9 & 1.2 & 17 & 0.7 & 3 \\
\hline Asgrow RX949W & White & 5.2 & 191 & 1.9 & 7 & 1.3 & 18 & 1.2 & 17 \\
\hline Zimmerman Z62W & White & 5.2 & 178 & 2.6 & 14 & 1.4 & 28 & 1.0 & 9 \\
\hline Vinyard VX 455W & White & 5.1 & 163 & 2.0 & 8 & 0.5 & 2 & 0.4 & 2 \\
\hline Clarkson Grain 5 Blue & Blue & 5.0 & 162 & 2.1 & 10 & 1.2 & 16 & 0.7 & 4 \\
\hline Zimmerman 1851W & White & 5.1 & 162 & 2.2 & 10 & 1.4 & 27 & 0.7 & 4 \\
\hline Zimmerman N71-T7 & Yellow & 5.0 & 152 & 1.2 & 3 & 0.7 & 4 & 0.4 & 2 \\
\hline Zimmerman Z76W & White & 4.9 & 141 & 1.9 & 8 & 0.8 & 7 & 0.7 & 4 \\
\hline FR827W $\times$ FR819W & White & 4.8 & 130 & 2.5 & 15 & 1.5 & 27 & 0.5 & 3 \\
\hline Zimmerman Z75W & White & 4.9 & 130 & 3.3 & 30 & 1.5 & 33 & 0.7 & 4 \\
\hline Diener D114W & White & 4.5 & 112 & 0.8 & 2 & 0.3 & 1 & 0.6 & 3 \\
\hline Clarkson Grain 4 Blue & Blue & 4.6 & 102 & 2.9 & 37 & 1.7 & 52 & 0.8 & 5 \\
\hline Clarkson Grain 2 Blue & Blue & 4.6 & 102 & 1.7 & 5 & 1.1 & 14 & 0.2 & 1 \\
\hline Zimmerman Z37 & Yellow & 4.5 & 91 & 1.8 & 6 & 0.9 & 7 & 0.3 & 1 \\
\hline Whisnand 50AW & White & 4.5 & 90 & 2.1 & 8 & 1.0 & 9 & 0.8 & 6 \\
\hline Dekalb DK665W & White & 4.3 & 77 & 1.3 & 5 & 0.8 & 5 & 0.4 & 2 \\
\hline FR1064 × LH287 & Yellow & 4.0 & 74 & 2.3 & 10 & 1.4 & 25 & 0.9 & 7 \\
\hline Zimmerman $1790 \mathrm{~W}$ & White & 4.1 & 74 & 1.8 & 6 & 0.7 & 5 & 0.4 & 1 \\
\hline FR3930T × LH185 & Yellow & 4.2 & 68 & 2.1 & 8 & 1.3 & 18 & 0.4 & 2 \\
\hline $\mathrm{NC}+4950 \mathrm{~W}$ & White & 3.9 & 67 & 1.6 & 5 & 0.9 & 7 & 0.3 & 1 \\
\hline FR810W $\times$ FR819W & White & 3.9 & 67 & 1.1 & 3 & 0.5 & 3 & 0.7 & 4 \\
\hline Vinyard VX 433W & White & 3.9 & 67 & 1.8 & 7 & 1.2 & 16 & 0.4 & 2 \\
\hline Dekalb DK703W & White & 3.9 & 62 & 2.2 & 9 & 1.3 & 19 & 1.1 & 12 \\
\hline $\mathrm{B} 73 \times \mathrm{Mo} 17$ & Yellow & 4.1 & 60 & 1.9 & 9 & 0.9 & 8 & 0.3 & 1 \\
\hline Vinyard VX 4359W & White & 3.9 & 59 & 1.7 & 6 & 1.1 & 14 & 0.6 & 3 \\
\hline Clarkson Grain 1 Blue & Blue & 3.9 & 55 & 1.6 & 5 & 0.9 & 8 & 0.3 & 1 \\
\hline Clarkson Grain 6 Blue & Blue & 4.0 & 54 & 2.3 & 11 & 1.2 & 16 & 0.1 & 0 \\
\hline FR1064 × LH185 & Yellow & 3.7 & 51 & 2.3 & 13 & 1.4 & 27 & 0.8 & 5 \\
\hline FR3930T $\times$ FR4911 & Yellow & 3.9 & 51 & 1.2 & 4 & 1.0 & 9 & 0.6 & 3 \\
\hline Zimmerman 1780W & White & 3.9 & 51 & 1.6 & 5 & 0.7 & 4 & 0.6 & 3 \\
\hline Whisnand 51AW & White & 3.8 & 48 & 0.7 & 2 & 0.4 & 2 & 0.2 & 0 \\
\hline Diener D115W & White & 3.7 & 46 & 1.4 & 4 & 0.7 & 4 & 0.7 & 6 \\
\hline $\mathrm{FR} 827 \mathrm{~W} \times \mathrm{FR} 828 \mathrm{~W}$ & White & 3.7 & 45 & 1.3 & 4 & 0.8 & 8 & 0.6 & 3 \\
\hline LH213 × FR9671 & Yellow & 3.8 & 45 & 1.7 & 5 & 1.0 & 10 & 0.6 & 3 \\
\hline Clarkson Grain 3 Blue & Blue & 3.8 & 45 & 2.1 & 8 & 1.0 & 9 & 0.2 & 1 \\
\hline FR1064 × FR4911 & Yellow & 3.7 & 41 & 1.9 & 7 & 1.2 & 16 & 0.9 & 9 \\
\hline Dekalb DK658 & Yellow & 3.5 & 36 & 1.3 & 4 & 1.3 & 18 & 0.4 & 2 \\
\hline Asgrow RX792W & White & 3.5 & 34 & 0.9 & 3 & 0.3 & 1 & 0.2 & 1 \\
\hline Pioneer 33T17 & Yellow & 3.2 & 33 & 0.6 & 2 & 0.2 & 1 & 0.3 & 1 \\
\hline Dekalb DK483 & Yellow & 2.8 & 31 & 2.4 & 12 & 1.5 & 31 & 0.8 & 6 \\
\hline Clarkson Grain 7 Blue & Blue & 3.4 & 30 & 1.1 & 3 & 0.3 & 1 & 0.4 & 2 \\
\hline Asgrow RX776W & White & 3.1 & 29 & 1.0 & 3 & 0.9 & 8 & 0.8 & 6 \\
\hline FR1064 × FR9661 & Yellow & 3.0 & 26 & 0.5 & 2 & 0.2 & 1 & 0.4 & 2 \\
\hline Vinyard VX 462W & White & 3.2 & 26 & 2.0 & 8 & 1.0 & 10 & 0.6 & 3 \\
\hline FR $1064 \times$ FR2108 & Yellow & 3.1 & 25 & 2.7 & 16 & 1.6 & 42 & 0.8 & 5 \\
\hline $\mathrm{FR} 810 \mathrm{~W} \times \mathrm{FR} 828 \mathrm{~W}$ & White & 3.1 & 25 & 1.4 & 4 & 0.8 & 6 & 0.5 & 2 \\
\hline $\mathrm{FR} 816 \mathrm{~W} \times \mathrm{FR} 825 \mathrm{~W}$ & White & 3.1 & 24 & 1.2 & 4 & 1.1 & 13 & 0.4 & 2 \\
\hline Pioneer 3346 & Yellow & 3.1 & 22 & 1.2 & 4 & 0.7 & 4 & 0.5 & 3 \\
\hline FR1064 × LH283 & Yellow & 2.4 & 17 & 1.7 & 5 & 0.9 & 7 & 0.0 & 0 \\
\hline Pioneer 3394 & Yellow & 2.6 & 15 & 1.6 & 6 & 0.6 & 3 & 0.4 & 2 \\
\hline $\mathrm{NC}+6990 \mathrm{~W}$ & White & 2.6 & 14 & 1.5 & 7 & 0.9 & 6 & 0.1 & 0 \\
\hline FR3930T $\times$ FR9661 & Yellow & 2.5 & 12 & 1.4 & 5 & 0.6 & 4 & 0.2 & 0 \\
\hline Asgrow RX901W & White & 2.4 & 12 & 1.4 & 4 & 0.9 & 9 & 0.6 & 3 \\
\hline FR3912 × FR4901 & Yellow & 2.0 & 8 & 1.4 & 4 & 0.3 & 1 & 0.1 & 0 \\
\hline Pioneer 32 Y 52 & Yellow & 1.9 & 8 & 1.1 & 3 & 0.6 & 3 & 0.2 & 1 \\
\hline Asgrow RX921W & White & 2.0 & 7 & 0.5 & 2 & 0.5 & 3 & 0.3 & 1 \\
\hline Dekalb DK635 & Yellow & 1.8 & 7 & 1.5 & 5 & 1.0 & 9 & 0.5 & 3 \\
\hline Asgrow RX764 & Yellow & 1.8 & 7 & 1.0 & 4 & 0.6 & 4 & 0.3 & 1 \\
\hline Pioneer X1128BW & White & 1.8 & 6 & 1.4 & 5 & 0.9 & 6 & 0.7 & 4 \\
\hline Pioneer $32 \mathrm{~K} 72$ & Yellow & 1.5 & 6 & 1.3 & 4 & 0.8 & 6 & 0.2 & 1 \\
\hline Pioneer $32 \mathrm{H} 39$ & Yellow & 1.7 & 5 & 2.0 & 7 & 0.9 & 8 & 0.5 & 2 \\
\hline Dekalb DK579 & Yellow & 1.5 & 5 & 1.6 & 5 & 1.2 & 14 & 0.5 & 2 \\
\hline FR3930T $\times$ LH283 & Yellow & 1.4 & 4 & 1.3 & 4 & 0.5 & 3 & 0.9 & 10 \\
\hline $\mathrm{NC}+4089 \mathrm{~W}$ & White & 1.4 & 4 & 1.6 & 5 & 1.2 & 15 & 1.1 & 11 \\
\hline Pioneer 34P93 & Yellow & 1.2 & 4 & 1.0 & 3 & 0.4 & 1 & 0.3 & 1 \\
\hline $\operatorname{LSD}(P=0.05)^{\mathrm{b}}$ & $\ldots$ & 1.3 & $\ldots$ & 1.3 & $\ldots$ & 0.4 & $\ldots$ & 0.4 & $\ldots$ \\
\hline
\end{tabular}

${ }^{a}$ Ears were inoculated by injecting $10 \mathrm{ml}$ of a $10^{6}$ spores $/ \mathrm{ml}$ spore suspension, comprising a mixture of six isolates, through the ear at the $\mathrm{R} 2$ growth stage. Data are the average of two replications. Fumonisin concentration transformation $(y=\ln [x+1])$ and Fusarium ear rot severity transformation $\left(y=\log _{10}[x+\right.$ 1]); $\mathrm{T}=$ transformed data and $\mathrm{N}=$ nontransformed data.

${ }^{\mathrm{b}}$ LSD $=$ least significant difference. 
Fumonisin concentration in grain of white, blue, and yellow food-grade dent corn hybrids ranged from 4 to 255,30 to 162 , and 4 to $252 \mu \mathrm{g} / \mathrm{g}$, respectively (Table 1 ). Pearson's correlation coefficient for fumonisin concentration in grain and severity of Fusarium ear rot was $r=0.83(P<0.0001)$ in 2000 .

Grand mean temperature for June, July, and August 2001 was $23.5^{\circ} \mathrm{C} \quad\left(0.06^{\circ} \mathrm{C}\right.$ above average). Rainfall and growing ${ }^{\circ} \mathrm{D}$ totaled $28.6 \mathrm{~cm}$ (3.3 cm below average) and $2,101^{\circ} \mathrm{D}$, respectively. Precipitation was greatest after pollination. Ear rot severity ranged from 0 to $17 \%$. Fumonisin concentration in grain ranged from 2 to 37 $\mu \mathrm{g} / \mathrm{g}$ (Table 1). Fumonisin concentration in grain of white, blue, and yellow foodgrade dent corn hybrids ranged from 2 to 30,3 to 37 , and 2 to $16 \mu \mathrm{g} / \mathrm{g}$, respectively (Table 1). Pearson's correlation coefficient for fumonisin concentration in grain and severity of Fusarium ear rot was $r=0.35$ $(P=0.0038)$ in 2001 .

Fumonisin concentration in grain was significantly affected by years $(P=$ $0.0004)$, hybrids $(P<0.0001)$, and the year-hybrid interaction $(P<0.0001)$. Fumonisin concentration was lowest in grain of Pioneer Brand 34P93 in 2000 (Table 1). Fumonisin concentration in grain of 14 other hybrids was not significantly different from 34P93 in 2000. In 2001, fumonisin concentration was lowest in grain of Asgrow RX921W and FR1064 $\times$ FR9661 (Table 1). Fumonisin concentration in grain of 40 other hybrids was not significantly different from RX921W and
FR1064 $\times$ FR9661 in 2001. Of the 15 hybrids that had low fumonisin concentration in grain in 2000, 14 also had low fumonisin concentration in 2001. Of these 14 hybrids, two with yellow kernels (FR3930T $\times$ LH283 and Pioneer Brand 34P93) had fumonisin concentration in grain $\leq 4 \mu \mathrm{g} / \mathrm{g}$ in both years (Table 1 ). Of the 14 most resistant hybrids, 7 (4 yellow and 3 white) had fumonisin concentration in grain $\leq 4 \mu \mathrm{g} / \mathrm{g}$ in 1 of the 2 years.

Severity of Fusarium ear rot was significantly affected by years $(P=0.002)$, hybrids $(P<0.0001)$, and the year-hybrid interaction $(P<0.0001)$. Ear size did not vary greatly among hybrids. Ear rot severity was lowest for Pioneer Brand 33T17 and FR1064 × FR9661 in 2000 (Table 1). Ear rot severity of 14 other hybrids was not significantly different from $33 \mathrm{~T} 17$ and FR1064 × FR9661 in 2000. Ear rot severity was lowest for FR1064 × LH283 in 2001 (Table 1). Ear rot severity of 29 other hybrids was not significantly different from FR1064 $\times$ LH283 in 2001. In all, 13 of 16 hybrids had low Fusarium ear rot in 2000 and 2001. All 13 of these hybrids had less than $5 \%$ ear rot in both years (Table 1).

Noninoculated trials. Grand mean temperature for June, July, and August 2001 was $24.9^{\circ} \mathrm{C}$ at Brownstown, $24.1^{\circ} \mathrm{C}$ at Carbondale, and $20.7^{\circ} \mathrm{C}$ at Dwight. Rainfall was 23.4, 36.8, and $14.2 \mathrm{~cm}$ at Brownstown, Carbondale, and Dwight, respectively. Fumonisin concentration in grain ranged from 0.6 to $1.0 \mu \mathrm{g} / \mathrm{g}$ (mean $0.7 \mu \mathrm{g} / \mathrm{g}$ ) in the Brownstown trial, 0.7 to
$3.7 \mu \mathrm{g} / \mathrm{g}$ (mean $1.4 \mu \mathrm{g} / \mathrm{g}$ ) in the Carbondale trial, and 0.7 to $14.6 \mu \mathrm{g} / \mathrm{g}$ (mean $3.6 \mu \mathrm{g} / \mathrm{g}$ ) in the Dwight trial (Table 2).

Fumonisin concentration in grain was significantly affected by locations $(P<$ $0.0001)$, hybrids $(P<0.0001)$, and the hybrid-location interaction $(P<0.0001)$. Fumonisin concentration was uniformly low in grain and did not differ significantly among hybrids at Brownstown $(P=0.58$; Table 2). Fumonisin concentration was lowest in grain from FR3930T $\times$ FR9661 at Dwight and from Zimmerman N71-T7 at Carbondale (Table 2). Fumonisin concentration did not differ significantly in grain from FR3930T $\times$ FR9661 and 8 other hybrids at Dwight, or from N71-T7 and 18 other hybrids at Carbondale. Eight (four yellow and four white hybrids) of nine hybrids tested had low fumonisin concentration at Dwight and Carbondale (Table 2). Fumonisin concentration was highest in grain from Zimmerman Z62W at Dwight and Pioneer Brand 33T90 at Carbondale (Table 2). Fumonisin concentration did not differ significantly in grain from Z62W and three other hybrids at Dwight or from 33T90 and two other hybrids at Carbondale. Three (one yellow, one blue, and one white) of four hybrids tested had high fumonisin concentration at Dwight and Carbondale (Table 2). All three hybrids had fumonisin concentration in grain $>7 \mu \mathrm{g} / \mathrm{g}$ at Dwight, but $<4 \mu \mathrm{g} / \mathrm{g}$ at Carbondale. Pearson's correlation coefficients for fumonisin concentration in grain from noninoculated trials in Dwight and

Table 2. Transformed $(\mathrm{T})$ and nontransformed $(\mathrm{N})$ fumonisin concentration $(\mu \mathrm{g} / \mathrm{g})$ in grain for 26 food-grade dent corn hybrids evaluated in noninoculated trials at Dwight, Carbondale and Brownstown, IL in 2001 ${ }^{\mathrm{a}}$

\begin{tabular}{|c|c|c|c|c|c|c|}
\hline \multirow[b]{2}{*}{ Hybrid } & \multicolumn{2}{|c|}{ Dwight } & \multicolumn{2}{|c|}{ Carbondale } & \multicolumn{2}{|c|}{ Brownstown } \\
\hline & $\mathbf{T}$ & $\mathbf{N}$ & $\mathbf{T}$ & $\mathbf{N}$ & $\mathbf{T}$ & $\mathbf{N}$ \\
\hline Zimmerman Z62W & 2.7 & 14.6 & 0.9 & 1.4 & 0.6 & 0.8 \\
\hline Pioneer 33T90 & 2.5 & 11.5 & 1.5 & 3.7 & 0.6 & 0.9 \\
\hline Clarkson Grain 1 Blue & 2.2 & 8.2 & 1.2 & 2.4 & 0.5 & 0.7 \\
\hline Dekalb DK665W & 2.1 & 7.2 & 1.3 & 2.5 & 0.5 & 0.7 \\
\hline Pioneer 34P93 & 1.8 & 5.3 & 1.0 & 1.6 & 0.5 & 0.6 \\
\hline Zimmerman Z64W & 1.7 & 4.4 & 1.0 & 1.8 & 0.6 & 0.8 \\
\hline Dekalb DK579 & 1.6 & 3.8 & 1.0 & 1.7 & 0.6 & 0.8 \\
\hline Asgrow RX764 & 1.4 & 3.1 & 0.8 & 1.3 & 0.5 & 0.7 \\
\hline Asgrow RX949W & 1.4 & 3.0 & 0.7 & 1.1 & 0.6 & 0.9 \\
\hline Pioneer 3394 & 1.4 & 2.9 & 0.8 & 1.3 & 0.6 & 0.8 \\
\hline Pioneer X1128BW & 1.4 & 2.9 & 0.8 & 1.3 & 0.5 & 0.7 \\
\hline Pioneer $32 \mathrm{H} 39$ & 1.3 & 2.8 & 0.9 & 1.5 & 0.6 & 0.8 \\
\hline FR3912 × FR4901 & 1.3 & 2.7 & 0.9 & 1.5 & 0.5 & 0.7 \\
\hline Zimmerman Z37 & 1.3 & 2.7 & 0.7 & 1.1 & 0.7 & 1.0 \\
\hline $\mathrm{FR} 827 \mathrm{~W} \times \mathrm{FR} 819 \mathrm{~W}$ & 1.3 & 2.6 & 0.6 & 0.8 & 0.6 & 0.9 \\
\hline $\mathrm{NC}+4089 \mathrm{~W}$ & 1.3 & 2.5 & 0.7 & 1.0 & 0.5 & 0.6 \\
\hline Whisnand 50AW & 1.3 & 2.5 & 0.6 & 0.9 & 0.5 & 0.7 \\
\hline Pioneer $32 \mathrm{~K} 72$ & 1.1 & 2.0 & 1.0 & 1.7 & 0.5 & 0.7 \\
\hline FR810W $\times$ FR819W & 1.0 & 1.8 & 0.6 & 0.9 & 0.5 & 0.7 \\
\hline Asgrow RX951W & 1.0 & 1.6 & 0.9 & 1.4 & 0.6 & 0.8 \\
\hline Asgrow RX921W & 1.0 & 1.6 & 0.7 & 1.1 & 0.5 & 0.7 \\
\hline $\mathrm{NC}+6990 \mathrm{~W}$ & 0.9 & 1.4 & 0.6 & 0.8 & 0.5 & 0.7 \\
\hline Zimmerman N71-T7 & 0.7 & 1.1 & 0.5 & 0.7 & 0.6 & 0.8 \\
\hline Asgrow RX901W & 0.7 & 1.0 & 0.6 & 0.8 & 0.5 & 0.6 \\
\hline FR3930T × LH185 & 0.6 & 0.9 & 0.6 & 0.9 & 0.6 & 0.8 \\
\hline FR3930T $\times$ FR9661 & 0.5 & 0.7 & 0.7 & 1.1 & 0.5 & 0.6 \\
\hline $\operatorname{LSD}(P=0.05)^{\mathrm{b}}$ & 0.7 & $\ldots$ & 0.4 & $\ldots$ & NS & $\ldots$ \\
\hline
\end{tabular}

${ }^{a}$ Data are the average of three replications. Fumonisin concentration transformation $(y=\ln [x+1])$.

${ }^{\mathrm{b}} \mathrm{LSD}=$ least significant difference, $\mathrm{NS}=$ not significant. 
inoculated trials in Urbana in 2000 or 2001 were $r=0.42(P=0.03)$ and $r=0.43(P=$ $0.03)$, respectively.

\section{DISCUSSION}

Food-grade dent corn hybrids with consistent high or low fumonisin concentration in grain were identified across years, locations, and inoculation treatments (Tables 1 and 2). For example, 14 hybrids tested had low fumonisin concentration in grain across two inoculated trials. Of these 14 hybrids, two hybrids had fumonisin concentration in grain $\leq 4 \mu \mathrm{g} / \mathrm{g}$ in both years. When Fusarium ear rot development is favored, the hybrids in this study with high fumonisin concentration in multiple inoculated trials likely will have unacceptable fumonisin levels in production fields. This becomes especially pertinent when grain is destined for human consumption, and no physical or chemical methods are deployed to reduce fumonisin contamination during processing.

There was some disparity among hybrid reactions to fumonisin accumulation in grain across years of inoculated trials (year-hybrid interaction, $P<0.0001$ ). Nevertheless, hybrids with highest or lowest fumonisin concentration in grain in 2000 generally had concordant highest or lowest fumonisin concentration in grain in 2001. Some disparity also was observed between hybrids with low or high fumonisin accumulation in inoculated trials and hybrids identified with low or high fumonisin accumulation in noninoculated trials. For example, Pioneer Brand 34P93 was among hybrids with low fumonisin concentration in grain in two inoculated trials. Although 34P93 had fumonisin concentration in grain $\leq 4 \mu \mathrm{g} / \mathrm{g}$ at inoculated trials, it had $5 \mu \mathrm{g} / \mathrm{g}$ when naturally infected at Dwight. Furthermore, Zimmerman $\mathrm{Z} 62 \mathrm{~W}$ was among the most susceptible hybrids identified in two inoculated trials and one noninoculated trial; however, Z62W was statistically among the hybrids with the lowest fumonisin concentrations in one of three noninoculated trials. This disparity in results could be due to the fact that ears in the noninoculated trials were machine harvested and were not visually inspected for Fusarium ear rot or any other physical damage. Hybrids may have had varying levels of insect damage at the Dwight location, which may have been why 34P93 had >4 $\mu \mathrm{g} / \mathrm{g}$ at the Dwight location but not in any of the inoculated trials.

Greater magnitude and range of fumonisin concentrations facilitate separation of genotypes. In this study, our inoculation technique enhanced disease development and allowed us to more successfully differentiate genotypes that could develop high fumonisin accumulation in grain compared to natural infection. For example, under natural infection at Dwight, Z62W had the highest fumonisin accumulation in grain and the three hybrids that were not significantly different from $\mathrm{Z} 62 \mathrm{~W}$ all had high fumonisin accumulation in grain following inoculation. Similarly, at Carbondale, Pioneer 33T90 had the highest fumonisin accumulation in grain and the two hybrids that were not significantly different from 33T90 all had high fumonisin accumulation in grain following inoculation.

Environmental conditions in the inoculated trial at Urbana, IL in 2000 favored greater disease development and greater magnitude and range of fumonisin concentrations than in the inoculated trials in 2001. Nevertheless, the magnitude and range in both inoculated trials were greater than in noninoculated trials, As a result, differences between hybrids were easier to detect in inoculated trails than in noninoculated trials. This suggests that our inoculation technique, which promotes severe disease development and fumonisin accumulation in grain, could help to eliminate the misclassification of hybrids as resistant when tested in environments that do not favor disease development.

We expect that most hybrids in this study that had fumonisin concentration in grain, with inoculation, $\leq 4 \mu \mathrm{g} / \mathrm{g}$ would have acceptable fumonisin concentrations in grain produced in most environments, without inoculation. An exception was Pioneer 34P93, which had $\leq 4 \mu \mathrm{g} / \mathrm{g}$ in inoculated trials but had $>4 \mu \mathrm{g} / \mathrm{g}$ in Dwight without inoculation. This example suggests that inoculation may not be completely satisfactory in identifying all maize hybrids that would be acceptable for foodgrade use in all environmental conditions. To circumvent this limitation, it is desirable to evaluate hybrids for several years or over several environments, with inoculation, and then to evaluate those hybrids in areas, such as the coastal areas of North Carolina, that consistently have conditions that favor fumonisin accumulation.

Fumonisin concentration in grain from inoculated trials was generally much higher than concentrations reported from naturally infected grain production fields in the Midwestern United States. Nonetheless, the fumonisin results achieved in this study were not unreasonably high, in that similar concentrations of naturally occurring fumonisin often occur in the southeastern United States. For example, fumonisin concentrations as high as $250 \mu \mathrm{g} / \mathrm{g}$ was reported in grain from naturally infected, commercially grown hybrids in North Carolina (17).

Grain from nine hybrids in 2000 and 33 hybrids in 2001 could have been graded as U.S.\#1 dent corn (14), because total kernels damaged by Fusarium ear rot was less than 3\% (Table 3). Despite low severity of

Table 3. Nontransformed fumonisin concentration in grain and Fusarium ear rot severity for 68 food-grade dent corn hybrids evaluated in inoculated trials at Urbana, IL in 2000 and 2001

\begin{tabular}{|c|c|c|c|c|c|c|c|}
\hline \multirow[b]{2}{*}{ Year, fumonisin $(\mu \mathrm{g} / \mathrm{g})$} & \multicolumn{7}{|c|}{ Ear rot $(\%)^{\mathbf{a}}$} \\
\hline & $<3$ & $3-5$ & $6-7$ & 8-10 & 11-15 & $>15$ & Percent $(\%)^{\mathrm{h}}$ \\
\hline \multicolumn{8}{|l|}{2000} \\
\hline$<2$ & 0 & 0 & 0 & 0 & 0 & 0 & 0 \\
\hline $2-4$ & 1 & 1 & 0 & 0 & 1 & 0 & 5 \\
\hline $5-10$ & 1 & 3 & 2 & 2 & 1 & 0 & 13 \\
\hline $11-20$ & 0 & 2 & 2 & 1 & 0 & 0 & 7 \\
\hline $21-30$ & 2 & 1 & 1 & 2 & 1 & 1 & 12 \\
\hline $31-60$ & 3 & 2 & 0 & 6 & 1 & 5 & 25 \\
\hline$>60$ & 2 & 4 & 3 & 1 & 1 & 15 & 38 \\
\hline Percent $(\%)^{\mathrm{b}}$ & 13 & 19 & 12 & 18 & 7 & 31 & 100 \\
\hline \multicolumn{8}{|l|}{2001} \\
\hline$<2$ & 0 & 0 & 0 & 0 & 0 & 0 & 0 \\
\hline $2-4$ & 15 & 6 & 2 & 1 & 0 & 0 & 35 \\
\hline $5-10$ & 17 & 10 & 2 & 1 & 2 & 1 & 49 \\
\hline $11-20$ & 1 & 4 & 2 & 1 & 0 & 0 & 12 \\
\hline $21-30$ & 0 & 2 & 0 & 0 & 0 & 0 & 3 \\
\hline $31-60$ & 0 & 1 & 0 & 0 & 0 & 0 & 1 \\
\hline$>60$ & 0 & 0 & 0 & 0 & 0 & 0 & 0 \\
\hline Percent $(\%)^{\mathrm{b}}$ & 49 & 34 & 9 & 4 & 3 & 1 & 100 \\
\hline
\end{tabular}

a Data are the average of two replicates. Numbers within the table are the number of food-grade dent corn hybrids that are in each category.

${ }^{b}$ Percent of hybrids in each category. 
Fusarium ear rot for these hybrids, fumonisin concentration in grain from 8 of 9 hybrids in 2000 and 18 of 33 hybrids in 2001 exceeded $4 \mu \mathrm{g} / \mathrm{g}$ (Table 3 ). This supports previous work that reported that high concentration of fumonisin can exist in asymptomatic kernels destined for human consumption $(6,31)$. A poor relationship between Fusarium ear rot and fumonisin accumulation in grain is supported by Pearson's correlation coefficients between fumonisin accumulation in grain and severity of Fusarium ear rot $r=0.83(P<$ $0.0001)$ in 2000 and $r=0.35(P=0.0038)$ in 2001. Therefore, fumonisin concentration cannot be determined by the amount of Fusarium ear rot. Thus, grain must be chemically tested to determine the fumonisin concentration.

Environmental differences in this study greatly effected hybrid performance related to Fusarium ear rot severity and fumonisin accumulation in grain. This is evident from data presented in Table 1 , in which a narrow subset (14 of 68 hybrids) of the most resistant hybrids had low fumonisin concentration in grain in 2000 , whereas a broader subset of hybrids (42 of 68 hybrids), including several hybrids identified as having moderate or high fumonisin accumulation in 2000, had low fumonisin concentration in grain in 2001 . This emphasizes the need to evaluate genotypes in multiple, inoculated trials. Conversely, this suggests that our inoculation technique may overcome low levels of natural resistance that otherwise might be expressed in environments that do not promote severe disease development. Nevertheless, our inoculation technique may be less likely to identify hybrids as resistant when they are actually susceptible in environments that favor fumonisin accumulation.

Traits such as tight husk leaves $(11,44)$ and prolonged silk survival $(15,16)$ could contribute to resistance of some genotypes by imposing a physical barrier between kernels and inoculum sources. Our inoculation technique consists of injecting inoculum through the husk leaves-a process that bypasses these physical barriers. Consequently, genotypes with "barriertype" mechanisms of resistance may be overlooked when evaluating genotypes for resistance in inoculated trials.

We did not identify any food-grade hybrids with very high levels of resistance to fumonisin accumulation. All of the hybrids in our experiment could have unacceptably high fumonisin concentrations when environmental conditions favor fumonisin accumulation. However, a few hybrids in this study had consistently low fumonisin concentrations of $<4 \mu \mathrm{g} / \mathrm{g}$. These hybrids are likely to perform well in most years when grown in the Midwestern United States. Unfortunately, none of the hybrids could be expected to have very low $(<2$ $\mu \mathrm{g} / \mathrm{g}$ ) fumonisin accumulation in grain when grown in environments that favor Fusarium ear rot and fumonisin accumulation. Thus, it is important to identify sources of high levels of resistance and begin the process of incorporating additional genes for resistance into commercially used germplasm.

\section{ACKNOWLEDGMENTS}

We thank S. R. Phillips and S. K. Sipp for assistance with field work and the University of Illinois Variety Testing program for planting and harvesting the Brownstown, Carbondale, and Dwight trials.

\section{LITERATURE CITED}

1. Anderson, B. M., and Dolezal, W. E. 1993. Prevalence and distribution of fumonisin in the United States. Pages 139-149 in: Proc. 48th Annu. Corn Sorghum Res. Conf Am. Seed Trade Assoc., Inc. Chicago.

2. Bennett, G. A., Richard, J. L., and Eckhoff, S. R. 1996. Pages 317-322 in: Distribution of Fumonisins in Food and Feed Products Prepared from Contaminated Corn, in Fumonisins in Food. L. Jackson, J. W. Devries, and L. B. Bullerman, eds. Plenum Press, New York.

3. Blackwell, B. A., Gilliam, J. T., Savard, M. E., Miller, J. D., and Duvick, J. P. 1999. Oxidative deamination of hydrolyzed fumonisin $\mathrm{B}_{1}\left(\mathrm{AP}_{1}\right)$ by cultures of Exophiala spinifera. Nat. Toxins 7:31-38.

4. Castelo, M. M., Sumner, S., and Bullerman, L. B. 1998. Occurrence of fumonisins in cornbased food products. J. Food Prot. 61:704-707.

5. Cheng, S. J., Jiang, Y. Z., Li, M. H., and Lo, H. Z. 1985. A mutagenic metabolite produced by Fusarium moniliforme isolated from Linxian County, China. Carcinogenesis 6:903-905.

6. Chu, F. S., and Li, G. Y. 1994. Simultaneous occurrence of fumonisin $B_{1}$ and other mycotoxins in moldy corn collected from the People's Republic of China in regions of high incidences of esophageal cancer. Appl. Environ. Microbiol. 60:847-852.

7. Clements, M. J. 2002. Resistance to fumonisins and Fusarium ear rot of corn. Ph.D. thesis, UMI number 3070279, Department of Crop Sciences, University of Illinois, Urbana.

8. Clements, M. J., Kleinschmidt, C. E., Maragos, C. M., Pataky, J. K., and White, D. G. 2003. Evaluation of inoculation techniques for Fusarium ear rot and fumonisin contamination of corn. Plant Dis. 87:147-153.

9. Clements, M. J., Maragos, C. M., Pataky, J. K., and White, D. G. 2004. Sources of resistance to fumonisin accumulation in grain and Fusarium ear and kernel rot of corn. Phytopathology 94:251-260.

10. Doko, M. B., and Visconti, A. 1994. Occurrence of fumonisins $B_{1}$ and $B_{2}$ in corn and corn-based human foodstuff in Italy. Food Addit. Contam. 11:433-439.

11. Farrar, J. J., and Davis, R. M. 1991. Relationships among ear morphology, western flower thrips, and Fusarium ear rot of corn. Phytopathology 81:661-666.

12. Flynn, T. J., Stack, M. E., Troy, A. L., and Chirtel, S. J. 1997. Assessment of the embryotoxic potential of the total hydrolysis product of fumonisin $\mathrm{B}_{1}$ using cultured organogenesis-staged rat embryos. Food Chem. Toxicol. 35:1135-1141.

13. Gelderblom, W. C. A., Jaskiewicz, K., Marasas, W. F. O., Thiel, P. G., Horak, R. M., Vleggaar, R., and Kriek, N. P. J. 1988. Fumonisins: Novel mycotoxins with cancer-promoting activity produced by Fusarium moniliforme. Appl. Environ. Microbiol. 54:18061811

14. Grain Inspection Packers and Stockyards 1996. U.S. Grain Standards Act Part 810.404 Subpart D: Grades and Grade Requirements for Corn.
On-line publication, No 60FR61196.

15. Headrick, J. M., and Pataky, J. K. 1991. Maternal influence on the resistance of sweet corn lines to kernel infection by Fusarium moniliforme. Phytopathology 81:268-274.

16. Headrick, J. M., Pataky, J. K., and Juvick, J. A 1990. Relationships among carbohydrate content of kernels, condition of silks after pollination, and the response of sweet corn inbred lines to infection by Fusarium moniliforme. Phytopathology 80:487-494.

17. Heiniger, R. W., James, V. G., and O'Neal, F E. 2002. Fumonisin: Growing problem in corn. N. C. Coop. Ex. Serv. On-line publication.

18. Hendrich, S., Miller, K. A., Wilson, T. M., and Murphy, P. A. 1993. Toxicity of Fusarium proliferatum-fermented nixtamalized corn-based diets fed to rats: Effect of nutritional status. J. Agric. Food Chem. 41:1649-1654

19. Hlywka, J. J., and Bullerman, L. B. 1999. Occurrence of fumonisin $\mathrm{B}_{1}$ and $\mathrm{B}_{2}$ in beer. Food Addit. Contam. 16:319-324.

20. Hopmans, E. C., and Murphy, P. A. 1993. Detection of fumonisins $\mathrm{B}_{1}, \mathrm{~B}_{2}$ and $\mathrm{B}_{3}$ and hydrolyzed fumonisin $\mathrm{B}_{1}$ in corn-containing foods. J. Agric. Food Chem. 41:1655-1658.

21. Jackson, L. S., Hlywka, J. J., Senthil, K. R., and Bullerman, L. B. 1996. Effect of thermal processing on the stability of fumonisins. Pages 345-353 in: Fumonisins in Food. L. Jackson, J. W. Devries, and L. B. Bullerman, eds. Plenum Press, New York.

22. Katta, S. K., Cagampang, A. E., Jackson, L. S., and Bullerman, L. B. 1997. Distribution of Fusarium molds and fumonisins in dry-milled corn fractions. Cereal Chem. 74:858-863.

23. Kleinschmidt, C. E., and White, D. G. 2003. Evaluation of two seed treatments for control of fumonisin in corn grain. (Abstr.) Phytopathology 93:S46.

24. Munkvold, G. P., and Desjardins, A. E. 1997 Fumonisins in maize, can we reduce their occurrence? Plant Dis. 81:556-565.

25. Murphy, P. A., Rice, L. G., and Ross, P. F. 1993. Fumonisin $B_{1}, B_{2}$ and $B_{3}$ content of Iowa, Wisconsin and Illinois corn and corn screenings. J. Agric. Food Chem. 41:263-268.

26. Musser, S. M., and Plattner, R. D. 1997. Fumonisin composition in cultures of Fusarium moniliforme, Fusarium proliferatum, and Fusarium nygami. J. Agric. Food Chem. 45:1169-1173.

27. Norred, W. P., Voss, K. A., Bacon, C. W., and Riley, R. T. 1991. Effectiveness of ammonia treatment in detoxification of fumonisin-contaminated corn. Food Chem. Toxicol. 29:815819.

28. Ott, R. L. 1993. An Introduction to Statistical Methods and Data Analysis. 4th ed. Duxbury Press, Belmont, CA.

29. Payne, G. A. 1999. Ear and kernel rots. Pages 45-46 in: Compendium of Corn Diseases, 3rd ed. D. G. White, ed. American Phytopathological Society, St. Paul, MN.

30. Pestka, J. J., Azcona-Olivera, J. I., Plattner, R. D., Minervini, F., Doko, M. B., and Visconti, A. 1994. Comparative assessment of fumonisin in grain-based foods by ELISA, GCMS, and HPLC. J. Food Prot. 57:169-172.

31. Rheeder, J. P., Marasas, W. F. O., Thiel, P. G. Sydenham, E. W., Shephard, G. S., and Schalkwyk, D. J. V. 1992. Fusarium moniliforme and fumonisins in corn in relation to human esophageal cancer in Transkei. Phytopathology 82:353-357.

32. Rice, L. G., and Ross, P. F. 1994. Methods for detection and quantitation of fumonisins in corn cereal products and animal excreta. J. Food Prot. 57:536-540.

33. Ritchie, S. W., Hanway, J. J., and Benson, G. O. 1997. How a corn plant develops. Spec. Rep. No. 48. Iowa State University of Science and Technology Coop. Ext. Serv. Ames.

34. Scott, D. H., Grogan, J., Gann, R., Everson, R. 
J., and Binkerd, K. 1992. Summary of 1989 , 1990, and 1991 pre-harvest corn ear rot/mycotoxin survey in Indiana. Purdue Univ. Agric. Exp. Stn. Bull 645. West Lafayette, IN.

35. Scott, P. M. 1993. Fumonisins. Int. J. Food Microbiol. 18:257-270.

36. Shelby, R. A., White, D. G., and Bauske, E. M. 1994. Differential fumonisin production in maize hybrids. Plant Dis. 78:582-584

37. Stack, M. E. 1998. Analysis of fumonisin $B_{1}$ and its hydrolysis product in tortillas. J. AOAC Int. 81:737-740.

38. Stack, M. E., and Eppley, R. M. 1992. Liquid chromatographic determination of fumonisins $\mathrm{B}_{1}$ and $\mathrm{B}_{2}$ in corn and corn products. J. AOAC Int. 75:834-837.

39. Sydenham, E. W., Shephard, G. S., Thiel, P. G., Marasas, W. F. O., and Stokenstrom, S.
1991. Fumonisin contamination of commercial corn based human foodstuffs. J. Agric. Food Chem. 39:2014-2018.

40. Sydenham, E. W., Thiel, P. G., Marasas, W. F. O., Shephard, G. S., Schalkwyk, D. J. V., and Koch, K. R. 1990. Natural occurrence of some Fusarium mycotoxins in corn from low and high esophageal cancer prevalence areas of the Transkei, South Africa. J. Agric. Food Chem. 38:1900-1903.

41. Thiel, P. G., Marasas, W. F. O., Sydenham, E. W., Shephard, G. S., and Gelderblom, W. C. A. 1992. The implications of naturally occurring levels of fumonisins in corn for human and animal health. Mycopathologia 117:3-9.

42. U.S. Food and Drug Administration/Center for Food Safety and Applied Nutrition (CFSAN) 2001. Background paper in support of fu- monisin levels in corn and corn products intended for human consumption. On-line publication, Docket number 00D-1277.

43. Voss, K. A., Bacon, C. W., Meredith, F. I., and Norred, W. P. 1996. Comparative subchronic toxicity studies of nixtamalized and water-extracted Fusarium moniliforme culture material. Food Chem. Toxicol. 34:623-632.

44. Warfield, C. Y., and Davis, R. M. 1996. Importance of the husk covering on the susceptibility of corn hybrids to Fusarium ear rot. Plant Dis. 80:208-210.

45. Woloshuk, C. P., Gann, R., and Everson, R. J. 2001. Fusarium ear rot and fumonisin contamination: An Indiana survey 1991-2001. in: Proc. 1st Fungal Genomics, 2nd Fumonisin Elimination and 14th Aflatoxin Elimination Workshops. Phoenix, AZ. 